\title{
Analysis of Undergraduate Students' Conceptual Consistency on Chemical Kinetics Using Four-Tier Chemistry Concept Inventory
}

\author{
Iriani Bakti ${ }^{1 *}$, Rizki Nur Analita ${ }^{1}$ \\ ${ }^{1}$ Chemistry Education Department, Lambung Mangkurat University, Banjarmasin, Indonesia \\ *Corresponding author. Email: irianib_kimia@ulm.ac.id
}

\begin{abstract}
The following research is aimed to investigate undergraduate students' conceptual understanding and their conceptual consistency in chemical kinetics. Moreover, it is also projected to classify the concepts based on easiness to be understood correctly or other that led to producing alternative concepts. This investigation had been carried out with 64 undergraduate students of the fifth semester of the Chemistry Education Department, Lambung Mangkurat University, who had finished the Reaction Rate topic. The instrument used was the Four-Tier Diagnostic Test and Chemistry Concept Inventory. Students' answers are classified based on their conceptual understanding. Besides, the answer's pattern showed the conceptual consistency that refers to their understanding. The whole students' conceptual consistencies were the basis that formed the conceptual model. The result shows that more students have alternative concepts than those who have misconceptions.
\end{abstract} Thus, only a few students have mastered the correct conceptions.

Keywords: chemical kinetics, chemistry concept inventory, conceptual consistency, four-tier diagnostic test, conceptual model

\section{INTRODUCTION}

The purpose of every learning is to improve students' skills or abilities, especially cognitive skills. Students' cognitive skills are generally affected by their conceptual understanding. On every student's cognitive learning outcomes that are scored under the average, the teacher tends to assume that students are terrible in mastering the concept of understanding. Even though, in the end, they understand the point but usually misapply on facing the same concept with different cases. The meaning of conceptual understanding cannot only be categorized into correct or incorrect conceptions, but there are more interpretations and alternatives, which are known as model concepts [1]. The conceptual model is the ability of students, which can be measured from the way they communicate about the concept and how they relate the concept mathematically [2]. There are three categories of model concepts, and they are correct concepts, alternative concepts, and misconceptions [3][4].

Misunderstanding of concepts, communication errors, learning errors, even errors in applying existing theories can be the cause of a different conceptual model from each student [3]. Students are said to have a good understanding of the concept that the individual can answer correctly every conceptual problem [4]. The majority of the case is learners' ability to answer the questions well; they want to answer them, but they had trouble when the context of the question changed although the cases are still on the same concept. Based on this, students cannot be said that they do not understand the concept because they can still understand the concept, but also cannot be said understand the concept because in the same concept and different context they cannot answer correctly. It requires the consistency of each student in answering questions so that the conception model owned by each individual is identified. Consistency in learning is students' ability to answer different context questions on the same concept [5]. In examining the consistency of students' conceptions genuinely, it is required an evaluation instrument that includes multiple representations, which are macroscopic, microscopic, and symbolic. One of them that widely used is a multiple-choice evaluation instrument called Concept Inventory [6]-[8]. Initially, Concept Inventory was an evaluation instrument developed to use in physics learning under the name of Force Concept Inventory (FCI) [9]. In chemistry learning, the evaluation instrument was developed under the name of the Chemistry Concept Inventory (CCI) [10], [11].

There are two choices of CCI evaluation instruments; they are whole multiple-choice tests and tiered multiple-choice tests. The whole multiple-choice test only gives true or false answers without further information about the reasons for the answers [12]-[14]. The two-tier diagnostic test, as the basis of a tiered multiple-choice test, can provide data in quantitative and qualitative at the same time. The quantitative data can be counted from the students' answers to the questions and the qualitative data can be analyzed from their reasons. However, the two-tier test has limited access to provide information about the students' level of conviction about every answer and reason [15]. Similar research explains that the two-tier test is challenging to use in distinguishing the correct answer because of understanding concepts or just guessing. As well as the 
incorrect answer, it is difficult to distinguish between misconceptions or alternative concepts [14].

Meanwhile, the use of a tiered multiple-choice test is the best alternative to identify students' conception models. The most effective tiered multiple-choice test is a four-tier diagnostic test. The four-tier test is a development of the two-tier test, in which the choice of questions' answers and reasons has each level of conviction [16]. Many studies have proven that the four-tier diagnostic test more efficient to analyze the result data and to determine the students' conceptual understanding. The answers, reasons, and the level of confidence provided by students through four-tier test are beneficial to know the level of conceptual model of each individual [16][14]-[17]

\section{FOUR-TIER CHEMISTRY CONCEPT INVENTORY DEVELOPMENT}

Researchers had developed the four-tier chemistry concept inventory instruments from various sources, such are research articles [12], [14], textbooks [18], or e-books [19][21]. Instruments from those sources were adapted to the concept of the material. The adaptation was carried out with consideration that the instruments were proven to be valid and reliable. Another validation was carried out by the team of physical chemistry lecturer who approved that the instruments and assessments could be used to examine the initial abilities of students.

The evaluation instrument consisted of eleven contexts of questions which are divided into five concepts. Each concept is processed into two to three questions with different context of representations, and they are macroscopic, microscopic, and symbolic representation. In Table 1, we can see the contexts of chemical kinetics questions which are used in research instruments:

Table 1. Context Questions on Chemical Kinetics Concepts

\begin{tabular}{|l|c|l|}
\hline \multicolumn{1}{|c|}{ Concept } & Number & \multicolumn{1}{c|}{ Problem Context } \\
\hline \multirow{2}{*}{$\begin{array}{l}\text { Definition, Graph, and Formula } \\
\text { of Reaction Rate }\end{array}$} & 1 & Graph and Definition of Reaction Rate. \\
\cline { 2 - 3 } & 2 & Formula and Calculation of Reaction Rate. \\
\cline { 2 - 3 } $\begin{array}{l}\text { Law of Rate and Determination of } \\
\text { Rate Reaction Order }\end{array}$ & 3 & Substance Coefficient and Reaction Rate Calculation. \\
\cline { 2 - 3 } Factors Affecting Reaction Rate & 5 & Order of Reaction Rate and Microscopic Condition of Substances. \\
\cline { 2 - 3 } & 6 & Order and Microscopic Condition of Substances from the time of reaction. \\
\hline \multirow{2}{*}{ Effect and Way of Catalyst } & 7 & Macroscopic Condition of Two Similar Substances with Different Forms. \\
\cline { 2 - 3 } & 9 & Graphics, Types, and Ways of Catalysts. \\
\hline Mechanism of Reaction Rate & 10 & Law of Rate and Mechanism of Reaction. \\
\cline { 2 - 3 } & 11 & Equation, Mechanism of Reaction, and Law of Rate. \\
\hline
\end{tabular}

The level of conviction used was in the form of a Likert scale that organized into three scales; they were Convinced, Doubtful, and Not Sure. The arrangement of three levels on the Likert scale was aimed to minimize the possibility of students confusing on determining their belief so that they were more focused on working at the questions given.

\section{METHOD}

The following research is in the form of descriptive analysis [22]. The factor investigated was the students' Conceptual understanding of chemical kinetics. The research sample was 64 students of the fifth semester of the Chemistry Education Department, Lambung Mangkurat University. Preliminary knowledge of the sample was used as a basis for answering the evaluation instruments provided in the form of the test. The study was conducted once without prior treatment. The purpose of the test without prior treatment was to obtain students' actual conceptual understanding based on their received knowledge.
The treatment for data analysis used three steps, and they are (1) analysis of test result and the level of conviction per the context of the question; (2) identification of alternative answers; (3) analysis of students' conception model. In the analysis of test results per the context of the question, the rules of [5] were used. Identification of alternative answers of students by using a method adapted from [14] is to describe all alternative answers on every context of the question and was accompanied by the percentage of the choices. The final step to analyze students' conception model is to use the rules adapted from [7] with the amount of modification. In the final result, students' abilities will be percentage into three categories, they are: (1) Understand the Concept; (2) Form the Alternative Concept; (3) Do not Understand the Concept. The level of students' conviction determines the depth of students' understanding of the concept. If the student answers "convinced" on the correct answer, it can be concluded that he understands the context of the given question. However, if the student answers "doubtful" or "not sure", it is necessary to make further identification about their understanding of the concept. 


\section{RESULT AND DISCUSSION}

\subsection{Analysis of Test Result and Conviction Level}

The test result for each question's context of 64 students had been obtained from their answers on the eleven items of questions. Each question consists of the answer and reason, as well as the level of conviction. The description of the data from the test result is presented in Table 2. Table 2 shows that the ability of students to understand concepts still tends to low. This can be seen from the context of the questions that were answered correctly get the lowest percentage $(28.69 \%)$, the context that produced alternative answers were in the second level of the percentage $(30.40 \%)$, and the context that were answered incorrectly receive the most significant percentage $(40.91 \%)$. In the eleven numbers of questions tested, the correct answer has the most significant percentage in the three problem contexts, and they are questions number 1 , 3 , and 7. The questions that produce the highest score in alternative answers are in numbers 2, 6, and 11. Questions number $4,5,8,9$, and 10 are obtained as the most significant percentage of the incorrect answers.

Table 2. Percentage of Test Result per Context of Question

\begin{tabular}{|c|c|c|c|c|}
\hline \multirow[t]{2}{*}{ Number } & \multirow{2}{*}{ Context of Question Indicator } & \multicolumn{3}{|c|}{ Percentage of Answers (\%) } \\
\hline & & Correct & Alternative & Incorrect \\
\hline 1 & Determine the graph and definition of reaction rate based on the graph. & 51.56 & 40.63 & 7.81 \\
\hline 2 & $\begin{array}{l}\text { Determine the formula and definition of reaction rate in the chemical reaction } \\
\text { equation. }\end{array}$ & 28.13 & 50.00 & 21.87 \\
\hline 3 & $\begin{array}{l}\text { Determine the score of reaction rate from the calculation substances in the } \\
\text { chemical reaction equation. }\end{array}$ & 48.44 & 34.37 & 17.19 \\
\hline 4 & $\begin{array}{l}\text { Determine the order and law of rates from the microscopic description of } \\
\text { substances. }\end{array}$ & 26.56 & 14.06 & 59.36 \\
\hline 5 & $\begin{array}{l}\text { Determine the order and microscopic condition of substances from the reaction } \\
\text { time. }\end{array}$ & 6.25 & 45.31 & 48.44 \\
\hline 6 & Determine the effect of temperature rise to the reaction rate and how it works. & 4.69 & 50.00 & 45.31 \\
\hline 7 & Determine factors that affect the reaction rate and how it works. & 82.81 & 9.38 & 7.81 \\
\hline 8 & $\begin{array}{l}\text { Determine the concept contained in the reaction graph of a catalyst and how it } \\
\text { works. }\end{array}$ & 7.81 & 34.38 & 57.81 \\
\hline 9 & $\begin{array}{l}\text { Determine the comparison of activation energy between reaction with and } \\
\text { without the catalyst. }\end{array}$ & 28.13 & 20.31 & 51.56 \\
\hline 10 & $\begin{array}{l}\text { Determine the law of rates through the reaction mechanism given along with } \\
\text { the rules. }\end{array}$ & 7.81 & 10.94 & 81.25 \\
\hline 11 & $\begin{array}{l}\text { Determine the reaction mechanism through the law of rates given along with } \\
\text { the rules. }\end{array}$ & 23.44 & 25.00 & 51.56 \\
\hline & Average Percentage & 28.69 & 30.40 & 40.91 \\
\hline
\end{tabular}

Further description and elaboration about students' conviction on their answer to the question and reason for each context of the question can be seen in Table 3. In Table 3, there are: "CA" that refers to Correct Answer, "AA" that refers to Alternative Answer, and "IA" that refers to Incorrect Answer. The description shows that on the question number 1,3 , and 7 , in which the correct answers get the highest percentage; students have a high conviction on their correct answers with a few percentages of doubtful and without any percentage of not sure. Students also own a high percentage of conviction toward the right reasons they choose with a few percentages of doubtful, and without a percentage of unsure. This indicates that most students certainty understand the concept of the context of the question.

Meanwhile, on question numbers 2 and 6 , in which alternative answers get the highest percentage, the level of students' conviction is quite high with a few percentage levels of doubtful and a little bit unsure. This result indicates that most students still did not fully understand the concepts in the context of the question. The alternative answers chosen by students can be the form of guessing. Further data analysis is needed to find out students' conceptual understanding.

In the context of the question in which the most significant percentage is on incorrect answers, most students have a relatively high level of conviction, both on the answer and the reasons for the questions. This high level of this conviction indicates that students do not understand the concept of the context of the given question. The more certain students on the incorrect answers, the more incorrect concepts they have formed. Further analysis needs to be carried out to find out the level of the misunderstanding of the concept they have. Further research needs to be carried out to correct the misconceptions based on the result of the following research analysis. 
Table 3. Percentage of Conviction Level per Context of Question

\begin{tabular}{|c|c|c|c|c|c|c|c|}
\hline \multirow{2}{*}{ Number } & \multirow{2}{*}{ Students' Answers } & \multicolumn{3}{|c|}{ Percentage of Answer Conviction Level } & \multicolumn{3}{|c|}{ Percentage of Reason Conviction Level } \\
\hline & & Conv.(\%) & Doubt. (\%) & Not Sure(\%) & Conv. (\%) & Doubt. (\%) & Not Sure(\%) \\
\hline \multirow[t]{3}{*}{1} & CA $(51.56 \%)$ & 48.44 & 3.13 & 0 & 40.63 & 10.94 & 0 \\
\hline & AA $(40.63 \%)$ & 32.81 & 7.81 & 0 & 31.25 & 9.37 & 0 \\
\hline & IA $(7.81 \%)$ & 7.81 & 0 & 0 & 7.81 & 0 & 0 \\
\hline \multirow[t]{3}{*}{2} & CA $(28.13 \%)$ & 15.63 & 12.50 & 0 & 15.63 & 10.94 & 1.56 \\
\hline & AA $(50 \%)$ & 35.94 & 12.50 & 1.56 & 32.81 & 15.63 & 1.56 \\
\hline & IA $(21.87 \%)$ & 14.06 & 7.81 & 0 & 9.37 & 12.5 & 0 \\
\hline \multirow[t]{3}{*}{3} & CA $(48.44 \%)$ & 40.63 & 7.81 & 0 & 37.50 & 10.94 & 0 \\
\hline & AA $(34.37 \%)$ & 15.63 & 17.18 & 1.56 & 10.94 & 20.31 & 3.13 \\
\hline & IA $(17.19 \%)$ & 7.81 & 6.25 & 3.13 & 6.25 & 9.37 & 1.56 \\
\hline \multirow[t]{3}{*}{4} & CA $(26.56 \%)$ & 23.44 & 1.56 & 1.56 & 18.75 & 7.81 & 0 \\
\hline & $\mathrm{AA}(14.06 \%)$ & 6.25 & 6.25 & 1.56 & 9.37 & 4.69 & 0 \\
\hline & IA $(59.36 \%)$ & 29.69 & 28.13 & 1.56 & 20.31 & 29.69 & 9.37 \\
\hline \multirow[t]{3}{*}{5} & $\mathrm{CA}(6.25 \%)$ & 4.69 & 1.56 & 0 & 3.13 & 1.56 & 1.56 \\
\hline & AA $(45.31 \%)$ & 26.56 & 17.19 & 1.56 & 14.06 & 25.00 & 6.25 \\
\hline & IA $(48.44 \%)$ & 28.13 & 20.31 & 0 & 17.19 & 21.87 & 9.38 \\
\hline \multirow[t]{3}{*}{6} & CA $(4.69 \%)$ & 4.69 & 0 & 0 & 4.69 & 0 & 0 \\
\hline & AA $(50 \%)$ & 39.06 & 9.38 & 1.56 & 28.13 & 18.75 & 3.13 \\
\hline & IA $(45.31 \%)$ & 34.37 & 10.94 & 0 & 26.56 & 18.75 & 0 \\
\hline \multirow[t]{3}{*}{7} & CA $(82.81 \%)$ & 79.68 & 3.13 & 0 & 70.31 & 10.94 & 1.56 \\
\hline & AA $(9.38 \%)$ & 7.81 & 1.56 & 0 & 7.81 & 1.56 & 0 \\
\hline & IA $(7.81 \%)$ & 3.13 & 4.69 & 0 & 3.13 & 4.69 & 0 \\
\hline \multirow[t]{3}{*}{8} & CA $(7.81 \%)$ & 6.25 & 1.56 & 0 & 3.13 & 4.69 & 0 \\
\hline & $\mathrm{AA}(34.38 \%)$ & 15.63 & 15.63 & 3.13 & 25.00 & 9.37 & 0 \\
\hline & IA $(57.81 \%)$ & 35.94 & 20.31 & 1.56 & 39.06 & 17.19 & 1.56 \\
\hline \multirow[t]{3}{*}{9} & CA $(28.13 \%)$ & 20.31 & 7.81 & 0 & 14.06 & 14.06 & 0 \\
\hline & AA $(20.31 \%)$ & 14.06 & 6.25 & 0 & 10.94 & 9.37 & 0 \\
\hline & IA $(51.56 \%)$ & 26.57 & 23.44 & 1.56 & 31.25 & 15.63 & 4.69 \\
\hline \multirow[t]{3}{*}{10} & $\mathrm{CA}(7.81 \%)$ & 4.69 & 3.13 & 0 & 6.25 & 1.56 & 0 \\
\hline & AA $(10.94 \%)$ & 3.12 & 7.81 & 0 & 4.69 & 6.25 & 0 \\
\hline & IA $(81.25 \%)$ & 50.00 & 31.25 & 0 & 50.00 & 29.69 & 1.56 \\
\hline \multirow[t]{3}{*}{11} & CA $(23.44 \%)$ & 17.19 & 6.25 & 0 & 14.06 & 7.81 & 1.56 \\
\hline & AA $(25.00 \%)$ & 9.38 & 12.50 & 3.13 & 4.69 & 15.63 & 4.69 \\
\hline & IA $(51.56 \%)$ & 29.69 & 20.31 & 1.56 & 23.44 & 28.13 & 0 \\
\hline
\end{tabular}

\subsection{Identification of Alternative Answers}

The following identification is made only on answers that classified as alternative, not incorrect ones. Students who had alternative answers are assumed to have different understanding concepts than those who had incorrect ones. The alternative answer given by students for all questions is outlined in Table 4. Here is the description of each alternative answer.

\subsubsection{Definition, Graph, and Formula of Reaction Rate Concept}

As shown about the result in question number 1, students tend to understand that reagent will always decrease, and products will always increase without any maximum limit or until the reaction stops. Therefore, the graph of the reaction rate never shows the intersection of the axis that states time, but it is parallel, which means the reaction will experience equilibrium, not stop. Students got incorrect reasons in translating about graph. The result indicated that students did not clearly understand how to read the graph. In question number 2, a quarter of the students got alternative answers in giving interpretation the formula of the reaction rate. They did not understand that a negative sign accompanies the rate reduction of reactant and a positive sign accompanies the rate formation of products. Nevertheless, they failed to interpret the formula and apply mathematical representation into definition of the reaction equation.

Similar to number 2, almost a quarter of the students gave the alternative solution to question number 3. Students incorrectly define the chemical reaction equation in mathematical understanding. They did not understand how to compare the calculation between substances and interpret them into some explanation. Students need to deepen their mathematical concepts in the context.

Percentage of the incorrect answers. 
Table 4. Percentage of Alternative Answers per Context of Question

\begin{tabular}{|c|c|c|c|c|}
\hline Number & The Answer & Reason & Alternative Answers & $\begin{array}{c}\text { Percentage } \\
(\%)\end{array}$ \\
\hline \multirow[t]{3}{*}{1} & \multirow[t]{2}{*}{ Correct (C) } & Incorrect (A) & $\begin{array}{l}\text { The student correctly determines the reaction rate Graph with the incorrect reason that } \\
\text { the concentration of reactants and products will continue to change until the reaction } \\
\text { stops. }\end{array}$ & 15.63 \\
\hline & & Incorrect $(\mathrm{C})$ & $\begin{array}{l}\text { The student correctly determines the reaction rate Graph with the incorrect reason that } \\
\text { the longer the time, the reactant will continue to decrease, and the product will continue } \\
\text { to grow. }\end{array}$ & 12.50 \\
\hline & $\begin{array}{l}\text { Incorrect } \\
(\mathrm{A} / \mathrm{B} / \mathrm{D})\end{array}$ & Correct (B) & $\begin{array}{l}\text { The student is incorrect to determine the rate of reaction Graph with the exact reason } \\
\text { that the concentration of reactant and product will continue to change until the reaction } \\
\text { equilibrates. }\end{array}$ & 12.50 \\
\hline \multirow[t]{4}{*}{2} & \multirow[t]{3}{*}{ Correct (A) } & Incorrect (A) & $\begin{array}{l}\text { The student correctly determines the reaction of the rate formula with the incorrect } \\
\text { reason that } 1 \mathrm{~mol} \text { of } \mathrm{A} \text { is consumed for every formation of } 2 \mathrm{~mol} \text { of } \mathrm{B} \text {, so the rate of } \\
\text { formation of } \mathrm{B} \text { is the half-time of the rate of A consumption. }\end{array}$ & 1.56 \\
\hline & & Incorrect (B) & $\begin{array}{l}\text { The student correctly determines the reaction of the rate formula with the incorrect } \\
\text { reason that } 1 \mathrm{~mol} \text { of } \mathrm{A} \text { is consumed for every formation of } 2 \mathrm{~mol} \text { of } \mathrm{B} \text {, so the rate of } \\
\text { formation of } \mathrm{B} \text { is twice times of the rate of A consumption. }\end{array}$ & 3.13 \\
\hline & & Incorrect (D) & $\begin{array}{l}\text { The student correctly determines the reaction of the rate formula with the incorrect } \\
\text { reason that } 2 \text { mol of A is consumed for every formation of } 1 \mathrm{~mol} \text { of } \mathrm{B} \text {, so the rate of } \\
\text { formation of } \mathrm{B} \text { is twice times of the rate of A consumption. }\end{array}$ & 18.75 \\
\hline & $\begin{array}{l}\text { Incorrect } \\
(\mathrm{B} / \mathrm{C})\end{array}$ & Correct (C) & $\begin{array}{l}\text { The student incorrectly determines the reaction of the rate formula with the correct } \\
\text { reason that } 2 \text { mol of } \mathrm{A} \text { is consumed for every formation of } 1 \mathrm{~mol} \text { of } \mathrm{B} \text {, so the rate of } \\
\text { formation of } \mathrm{B} \text { is the half-time of the rate of A consumption. }\end{array}$ & 26.56 \\
\hline \multirow[t]{4}{*}{3} & \multirow[t]{3}{*}{ Correct (C) } & Incorrect (B) & $\begin{array}{l}\text { The student correctly determines the score of the rate of oxygen with the incorrect } \\
\text { reason that the rate of oxygen consumption is one-three times the rate of formation of } \\
\text { ozone gas. }\end{array}$ & 23.44 \\
\hline & & Incorrect (C) & $\begin{array}{l}\text { The student correctly determines the score of the rate of oxygen with an incorrect } \\
\text { 8las that the rate of formation of ozone gas is half times of the rate of consumption of } \\
\text { oxygen gas. }\end{array}$ & 1.56 \\
\hline & & Incorrect (D) & $\begin{array}{l}\text { The student correctly determines the score of the rate of oxygen with an incorrect 8las } \\
\text { that ozone gas formation rate is twice times of the rate of consumption of oxygen gas. }\end{array}$ & 1.56 \\
\hline & Incorrect (A) & Correct $(\mathrm{A})$ & $\begin{array}{l}\text { The student is incorrect to determine the score of the rate of oxygen the right reason } \\
\text { that the rate of consumption of oxygen gas is one and a half times the rate of formation } \\
\text { of ozone gas. }\end{array}$ & 7.81 \\
\hline \multirow[t]{4}{*}{4} & \multirow[t]{3}{*}{ Correct (A) } & Incorrect (A) & $\begin{array}{l}\text { The student correctly determines the law of reaction rates with the incorrect reason that } \\
\text { the ratio of each A substance and B substance is always the same as the ratio of the } \\
\text { reaction rate. }\end{array}$ & 3.13 \\
\hline & & Incorrect (C) & $\begin{array}{l}\text { The student correctly determines the law of reaction rates for the incorrect reason that } \\
\text { the ratio of B substance is always static, while the ratio of A substance is two times } \\
\text { comparing the reaction rate. }\end{array}$ & 3.13 \\
\hline & & Incorrect (D) & $\begin{array}{l}\text { The student is correct to determine the law of reaction rates for the incorrect reason that } \\
\text { the ratio of each A substance and B substance are two times comparing the reaction } \\
\text { rate. }\end{array}$ & 1.56 \\
\hline & $\begin{array}{l}\text { Incorrect } \\
(\mathrm{B} / \mathrm{C})\end{array}$ & Correct (B) & $\begin{array}{l}\text { The student incorrectly determines the law of reaction rates with the exact reason that } \\
\text { the ratio of A substance is always static, while the ratio of B substance is two times } \\
\text { comparing the reaction ratio. }\end{array}$ & 6.25 \\
\hline \multirow[t]{4}{*}{5} & \multirow[t]{3}{*}{ Correct (B) } & Incorrect (A) & $\begin{array}{l}\text { The student correctly determines the microscopic representation with a incorrect reason } \\
\text { that the } \mathrm{P} \text { atom has a reaction order of } 1 \text { and the } \mathrm{Q} \text { atom has the reaction order of } 0 \text {, so it } \\
\text { does not affect the product. }\end{array}$ & 1.56 \\
\hline & & Incorrect (B) & $\begin{array}{l}\text { The student correctly determines the microscopic representation with a incorrect reason } \\
\text { that the } \mathrm{P} \text { atom has a reaction order of } 2 \text { and the } \mathrm{Q} \text { atom has the reaction order of } 0 \text {, so it } \\
\text { does not affect the product. }\end{array}$ & 9.38 \\
\hline & & Incorrect (C) & $\begin{array}{l}\text { The student correctly determines the microscopic representation with a incorrect reason } \\
\text { that the } \mathrm{P} \text { atom has a reaction order of } 1 \text {, and the } \mathrm{Q} \text { atom is a product, so it does not } \\
\text { have a reaction order. }\end{array}$ & 4.69 \\
\hline & $\begin{array}{l}\text { Incorrect } \\
\text { (C / D ) }\end{array}$ & Correct (D) & $\begin{array}{l}\text { The student incorrectly specifies a microscopic representation with a correct 8las that } \\
\text { the } \mathrm{P} \text { atom has a reaction order of } 2 \text { and } \mathrm{Q} \text { is a product, so it does not have a reaction } \\
\text { order. }\end{array}$ & 29.69 \\
\hline
\end{tabular}


Table 4. (Continued)

\begin{tabular}{|c|c|c|c|c|}
\hline Number & The Answer & Reason & Alternative Answers & $\begin{array}{l}\text { Percentage } \\
(\%)\end{array}$ \\
\hline \multirow[t]{5}{*}{6} & \multirow[t]{4}{*}{ Correct (B) } & Incorrect (A) & $\begin{array}{l}\text { The student correctly determines the factor of temperature rise to the rate with the } \\
\text { incorrect reason that the rise in temperature increases the average kinetic energy of each } \\
\text { molecule. }\end{array}$ & 7.81 \\
\hline & & Incorrect (B) & $\begin{array}{l}\text { The student correctly determines the factor of temperature rise to the rate with the } \\
\text { reason that the temperature rise can increase the average rate of each molecule. }\end{array}$ & 14.06 \\
\hline & & Incorrect $(\mathrm{C})$ & $\begin{array}{l}\text { The student correctly determines the factor of temperature rise to the rate with the } \\
\text { incorrect reason that the rise in temperature can increase the number of collisions } \\
\text { between molecules at a particular time. }\end{array}$ & 21.88 \\
\hline & & No Reason & $\begin{array}{l}\text { The student correctly determines the factor of temperature rise to the reaction rate, but } \\
\text { cannot give a reason. }\end{array}$ & 1.56 \\
\hline & $\begin{array}{l}\text { Incorrect } \\
(\mathrm{A} / \mathrm{C})\end{array}$ & Correct (D) & $\begin{array}{l}\text { The student incorrectly determines the factor of temperature rise to the rate with the } \\
\text { right reason that the temperature rise can increase the number of molecules that have } \\
\text { more energy than the activation energy. }\end{array}$ & 4.69 \\
\hline \multirow[t]{3}{*}{7} & \multirow[t]{3}{*}{ Correct (A) } & Incorrect $(\mathrm{A})$ & $\begin{array}{l}\text { The student correctly determines the factor that affects the rate by an incorrect factor } \\
\text { that the reaction is accelerated due to lower activation of energy and reagents that do } \\
\text { not require orientation to a possible collision. }\end{array}$ & 3.13 \\
\hline & & Incorrect $(\mathrm{C})$ & $\begin{array}{l}\text { The student correctly determines factor that affects the rate by incorrect reason that the } \\
\text { reaction is accelerated due to the increase in the velocity of the particles of the reactants } \\
\text { at higher temperatures. }\end{array}$ & 3.13 \\
\hline & & Incorrect (D) & $\begin{array}{l}\text { The student correctly determines the factor that affects the rate by incorrect reason that } \\
\text { the reaction is accelerated because the concentration of reactants will increase the } \\
\text { pressure of the oxygen gas, so the number of effective collisions also increases. }\end{array}$ & 3.13 \\
\hline \multirow[t]{4}{*}{8} & \multirow[t]{3}{*}{ Correct (D) } & Incorrect (A) & $\begin{array}{l}\text { The student correctly answers the question about catalyst with the incorrect reason that } \\
\text { the catalyst decreases the barrier energy of the reaction and increases the frequency of } \\
\text { collision of the reacting molecules. }\end{array}$ & 6.25 \\
\hline & & Incorrect (B) & $\begin{array}{l}\text { The student correctly answers the question about the catalyst with the incorrect reason } \\
\text { that the catalyst decreases the barrier energy of the reaction by giving way to lower } \\
\text { enthalpy changes. }\end{array}$ & 7.81 \\
\hline & & Incorrect $(\mathrm{C})$ & $\begin{array}{l}\text { The student correctly answers the question about the catalyst with the incorrect reason } \\
\text { that the catalyst decreases the barrier energy from the reaction without changing the } \\
\text { reaction mechanism. }\end{array}$ & 10.94 \\
\hline & $\begin{array}{l}\text { Incorrect } \\
(\mathrm{A} / \mathrm{C})\end{array}$ & Correct (D) & $\begin{array}{l}\text { The student incorrectly answers the question about catalysts with the correct reason that } \\
\text { catalysts decrease the barrier energy of a reaction by changing the reaction mechanism. }\end{array}$ & 9.38 \\
\hline \multirow{2}{*}{9} & \multirow{2}{*}{ Correct (C) } & Incorrect (D) & $\begin{array}{l}\text { The student correctly answers the question about the score of activation energy } \\
\text { with incorrect energy that the reaction with the catalyst goes through three stages, } \\
\text { where the stage at } E_{\mathrm{a} 3} \text { is the deciding stage because the score is smaller than } E_{\mathrm{a} 1} \text { and } E_{\mathrm{a} 2} \text {, } \\
\text { while the third score is smaller than } E_{\mathrm{a}} \text {. }\end{array}$ & 10.94 \\
\hline & & No Reason & $\begin{array}{l}\text { The student correctly answers the questions about the score of activation energy, but } \\
\text { cannot give a reason. }\end{array}$ & 1.56 \\
\hline \multirow[t]{2}{*}{10} & Correct (B) & Incorrect (A) & $\begin{array}{l}\text { The student correctly determines the law of rate with the incorrect reason that } \\
\text { propanone and iodine are reagents that are included in the reaction of determining the } \\
\text { rate. }\end{array}$ & 1.56 \\
\hline & $\begin{array}{l}\text { Incorrect } \\
(\mathrm{A} / \mathrm{C})\end{array}$ & Correct (B) & $\begin{array}{l}\text { The student incorrectly determines the law of rates with the right reason that propanone } \\
\text { and acid are reagents that are included in the reaction of determining the rate. }\end{array}$ & 9.38 \\
\hline \multirow[t]{4}{*}{11} & \multirow[t]{3}{*}{ Correct (B) } & Incorrect (B) & $\begin{array}{l}\text { The student correctly determines the reaction mechanism with the incorrect reason that } \\
\text { the acid acts as a catalyst and reacts to hydrogen peroxide in the step of determining the } \\
\text { rate. }\end{array}$ & 10.94 \\
\hline & & Incorrect (C) & $\begin{array}{l}\text { The student correctly determines the reaction mechanism with the incorrect reason that } \\
\text { iodide ions act as catalysts and react to hydrogen peroxide, but do not react with acids } \\
\text { in the step of determining the rate. }\end{array}$ & 4.69 \\
\hline & & Incorrect (D) & $\begin{array}{l}\text { The student correctly determines the reaction mechanism with the incorrect reason that } \\
\text { iodide ions act as catalysts and react to hydrogen peroxide and acids in the step of } \\
\text { determining the rate. }\end{array}$ & 4.69 \\
\hline & Incorrect $(\mathrm{C})$ & Correct (A) & $\begin{array}{l}\text { The student incorrectly determines the reaction mechanism with the right reason that } \\
\text { the acid acts as a catalyst and does not react to hydrogen peroxide or iodide ions in the } \\
\text { step of determining the rate. }\end{array}$ & 4.69 \\
\hline
\end{tabular}




\subsubsection{Law of Rate and Determination of Rate Reaction Order Concept}

Chemical processes in question number 4 are given as the microscopic condition of substances. The context of the question is intended to determine the understanding of reaction order in microscopic representation. During this time, students were asked to find the reaction order based on the picture of spheres with specific color and amount. Meanwhile, the rate of reaction is given in the form of numerical comparison. Most students found difficulty in determining reaction orders because they are hampered by the questions in the microscopic representation, not in numeric one.

The concept given in question number 5 is similar to question number 4 , which is in the form of microscopic representation of a substance. There are some pictures of balls with particular color and amount that compared to the reaction time required, and then students were asked to determine the color and number of balls at a particular time. In this case, students were still facing difficulties because they were hampered by microscopic representation of the question. Based on the answers of the questions given, students must be more critical in understanding how the microscopic condition of a reaction occurs and improve their literacy abilities.

\subsubsection{Factors Affecting Reaction Rate Concept}

Question number 6 is intended to determine how increasing temperatures can accelerate the reaction. There are some pictures of substances in microscopic representation and the specific time in every picture. Students tend to know the effect of temperature on the reaction rate, but they failed to explain the specific reason of how that happened. Their understanding was limited to the reason that the increase in temperature can increase the kinetic energy of a substance, the average rate of a molecule, and the number of the collision.

There are only a few students that got the alternative answers for question number 7 . In the question, there are pictures of two objects in different shapes. The pictures show the combustion reaction that occurs between those two objects. The alternative answers indicated that the understanding of students' conception in macroscopic representation is better than their conception in microscopic one.

\subsubsection{Effect and Way of Catalyst Concept}

Quite a lot of students had alternative answers to question number 8 . The context states about the basic understanding of catalysis. Students did not understand deeply about the kinds of catalysts and how it works to affect the reaction rate. They need to learn more that with the addition of a catalyst, the reaction takes place more quickly because of dividing the reaction into several mechanisms and forming inter substances, so that the activation energy of the reaction decreases compared to the previous reaction. The concept given in question number 9 is about activation energy in the reaction mechanism. Many students got alternative answers. That result indicated that students' understanding of the concept of activation energy between reaction with and without the catalyst is still low. The amount of activation energy in reaction mechanism that uses catalysts has no correlation with activation energy in reaction mechanism without catalysts. Activation energy stands alone by every reaction.

\subsubsection{Mechanism of Reaction Rate Concept}

In question number 10, there is a reaction equation. The reaction is divided into several mechanisms in the form of slow and fast stages. From that question, students were asked to determine the rate law and substances that act as reactants. Most of the students only thought that the reaction rate law equation consists of all reactants occur. Many students experienced misconceptions by stating that the catalyst does not react at all.

Similar to number 10, question number 11 requires students to be able to give a reaction mechanism from the rate law equation. Students gave several alternative answers. Most of them stated that all of the reactants are substances in the step of determining the rate law equation. Their answers indicated that the understanding of students conception in reaction mechanism was shallow and needed to be taught more deeply.

\subsection{Analysis of Conceptual Model}

The determination of the conceptual model owned by students is adapted from the analysis used by [7]. The following tables are the description of students' conceptual consistency.

Table 5. Percentage of Students' Conceptual Model on the First Concept

\begin{tabular}{|c|l|c|c|c|c|c|c|c|}
\hline Number & \multicolumn{1}{|c|}{ Material Concept } & $\begin{array}{c}\text { Percentage of } \\
\text { Understanding } \\
\text { Concepts (\%) }\end{array}$ & \multicolumn{3}{|c|}{$\begin{array}{c}\text { Percentage of Forming } \\
\text { Alternative Concepts (\%) }\end{array}$} & \multicolumn{2}{c|}{$\begin{array}{c}\text { Percentage of Not } \\
\text { Understanding Concepts (\%) }\end{array}$} \\
\hline $1,2,3$ & $\begin{array}{l}\text { Definition, chart and } \\
\text { formulas of the reaction } \\
\text { rate. }\end{array}$ & 4.69 & 34.38 & 21.88 & 18.75 & 17.19 & 3.13 & False 2 \\
\hline
\end{tabular}


Table 6. Percentage of Students' Conceptual Model on the Second to Fifth Concept

\begin{tabular}{|c|c|c|c|c|c|c|}
\hline \multirow[t]{2}{*}{ Number } & \multirow[t]{2}{*}{ Material Concept } & \multirow{2}{*}{\begin{tabular}{|c|} 
Percentage of \\
Understanding \\
Concepts $(\%)$ \\
\end{tabular}} & \multicolumn{2}{|c|}{\begin{tabular}{|c|} 
Percentage of Forming \\
Alternative Concepts $(\%)$
\end{tabular}} & \multicolumn{2}{|c|}{$\begin{array}{c}\text { Percentage of Not } \\
\text { Understanding Concepts }(\%)\end{array}$} \\
\hline & & & False 1 & False 2 & False 3 & False 4 \\
\hline 4,5 & $\begin{array}{l}\text { The law of the rate and determination } \\
\text { of the reaction order. }\end{array}$ & 0 & 12.50 & 28.13 & 28.13 & 31.25 \\
\hline 6,7 & $\begin{array}{l}\text { Factors that influence the rate of } \\
\text { reaction. }\end{array}$ & 3.13 & 40.63 & 45.31 & 9.38 & 1.56 \\
\hline 8,9 & Effect and how the catalyst works. & 4.69 & 9.38 & 25.00 & 29.69 & 31.25 \\
\hline 10,11 & Mechanism of the reaction rate. & 1.56 & 6.25 & 23.44 & 26.56 & 42.19 \\
\hline
\end{tabular}

Table 7. Percentage of Students' Average Conceptual Model

\begin{tabular}{|c|c|c|c|}
\hline & $\begin{array}{c}\text { Understanding } \\
\text { Concept }\end{array}$ & $\begin{array}{c}\text { Forming Alternative } \\
\text { Concept }\end{array}$ & $\begin{array}{c}\text { Not Understanding } \\
\text { Concept }\end{array}$ \\
\hline $\begin{array}{c}\text { Average Percentage } \\
(\%)\end{array}$ & 2.81 & 56.56 & 40.63 \\
\hline
\end{tabular}

Questions number 1 to 3 belong to the first concept, in which each question context consists of two points, they are the choice of the answer of questions and choice of reasons. Six points can be calculated in the first concept. If a student answered all of the concepts correctly, then he/ she is categorized as an understanding concept. If a student answered one to four points incorrectly, then he/ she is categorized as forming alternative concept. If a student answered five to six points incorrectly, then he/ she is categorized as not understanding concept.

The second to fifth concepts consist of the context of questions number 4 to number 11 . Since each concept consists of two question contexts, then each of these concepts has four points that can be calculated. If the student can answer four points correctly, then he/ she is classified as an understanding concept. If the number of incorrect answers given is one or two points, he is categorized as forming alternative concept. But if the incorrect answer is three or four points, then he is classified as a not understanding concept.

The description of students' average conceptual model can be seen in Table 7 . The percentage of students who categorized as an understanding concept is $2.81 \%$ with all convinced choice. This indicates that students in those categories understand the concept well. The result of the forming alternative concept is $56.56 \%$, with the level of conviction is divided into convinced, doubtful, and not sure. Meanwhile, the students who classified as a not understanding concept is $40.63 \%$. Many studies have stated that the lack of conceptual understanding occurs in chemical kinetics material. The lack of students' understanding can be an alternative concept or they do not understand the concept of material [23]-[26].

The lack of students' understanding of the chemical kinetics concept can also occur due to teaching materials that contain misconceptions [27] or even because the teacher has not enough knowledge to understand the concept deeply. It is quite surprising when there is research that says that many teachers who have not yet mastered the concept well, as said in [28] or [29]. It will not be useful for learning if the lack of understanding occurs to the teachers. Therefore, before it happens, the lack of conceptual understanding of the chemical kinetics material should be addressed immediately by a pre-service teacher.

\section{CONCLUSION}

The answers given by students to the eleven question contexts are divided into correct answers, alternative answers, and incorrect answers. Most students answered correctly in the context of the question number 1,3 , and 7 . Alternative answers received the most significant percentage in the context of question numbers 2 and 6 . Meanwhile, in the context of the question number 4, 5, 8, 9,10 , and 11 , some of the students still choose incorrect answers. Students' conceptual model is determined based on five concepts that outline the questions being tested. Most students were forming alternative concept on the first and third concepts, while for the second, fourth, and final concepts are mostly classified as not understanding concepts.

The results show that the Chemistry Concept Inventory instrument was quite accurate to assess students' conceptual understanding deeply, especially in a multirepresentation context. In the meantime, the Four-Tier Diagnostic Test instrument can be used as a substitute for interviews with consideration of a more effective and time-efficient process. Even though the result of this study was valid and reliable enough, however, researchers are planning to analyze students' conceptual understanding with interviews. Researchers try to dig deeper into problems in chemistry material, so they can decide the best in solving the problems. 


\section{ACKNOWLEDGMENT}

Researchers would like to thank all undergraduate students for their willingness to help carry out this research study. Thank also goes to other researchers or scientific articles who are willing to share their instruments for the sake of our research and lecturers who are willing to give their time and energy as instruments validators. Researchers also convey special thanks to all academicians in Lambung Mangkurat University and Malang State University who helped in the publication of this research article.

\section{REFERENCES}

[1] M. Chhabra and B. Baveja, "Exploring Minds: Alternative Conceptions in Science," Procedia - Soc. Behav. Sci., vol. 55, pp. 1069-1078, 2012.

[2] I. M. Greca and M. A. Moreira, "Mental models, conceptual models, and modelling," Int. J. Sci. Educ., vol. 22, no. 1, pp. 1-11, 2000.

[3] C. J. Wenning, "Dealing more effectively with alternative conceptions in science," J. Phys. Teach. Educ. Online, vol. 5, no. 1, pp. 11-19, 2008.

[4] A. Tongchai, M. D. Sharma, I. D. Johnston, K. Arayathanitkul, and C. Soankwan, "Consistency of students' conceptions of wave propagation: Findings from a conceptual survey in mechanical waves," Phys. Rev. Spec. Top. - Phys. Educ. Res., vol. 7, no. 2, pp. 1-11, 2011.

[5] A. Savinainen and J. Viiri, "The force concept inventory as a measure of students conceptual coherence," Int. J. Sci. Math. Educ., vol. 6, no. 4, pp. 719-740, 2008.

[6] S. Krause, J. Birk, R. Bauer, B. Jenkins, and M. J. Pavelich, "Development, testing, and application of a chemistry concept inventory," Proc. - Front. Educ. Conf., pp. 103-107, 2005.

[7] P. Nieminen, A. Savinainen, and J. Viiri, "Force concept inventory-based multiple-choice test for investigating students' representational consistency," Phys. Rev. Spec. Top. - Phys. Educ. Res., vol. 6, no. 2, pp. 1-12, 2010.

[8] M. A. Undersander, T. J. Lund, L. S. Langdon, and M. Stains, "Probing the question order effect while developing a chemistry concept inventory," Chem. Educ. Res. Pract., vol. 18, no. 1, pp. 45-54, 2017.

[9] D. Hestenes, M. Wells, and G. Swackhamer, "Force concept inventory," Phys. Teach., vol. 30, no. 3, pp. 141-158, 1992.

[10] R. A. Kruse and G. H. Roehrig, "A Comparison Study: Assessing Teachers' Conceptions with the Chemistry Concepts Inventory," J. Chem. Educ., vol. 82, no. 8, p. 1246, 2009.
[11] M. Dick-Perez, C. J. Luxford, T. L. Windus, and T. Holme, "A Quantum Chemistry Concept Inventory for Physical Chemistry Classes," J. Chem. Educ., vol. 93, no. 4, pp. 605-612, 2016.

[12] D. Wren and J. Barbera, "Gathering evidence for validity during the design, development, and qualitative evaluation of Thermochemistry Concept Inventory items," J. Chem. Educ., vol. 90, no. 12, pp. 1590-1601, 2013.

[13] D. Sands, M. Parker, H. Hedgeland, S. Jordan, and R. Galloway, "Using concept inventories to measure understanding," High. Educ. Pedagog., vol. 3, no. 1, pp. 173-182, 2018.

[14] Y. K. Yan and R. Subramaniam, "Using a multi-tier diagnostic test to explore the nature of students' alternative conceptions on reaction kinetics," Chem. Educ. Res. Pract., vol. 19, no. 1, pp. 213-226, 2018.

[15] D. C. Yang and Y. C. Lin, "Assessing 10- to 11year-old children's performance and misconceptions in number sense using a four-tier diagnostic test," Educ. Res., vol. 57, no. 4, pp. 368-388, 2015.

[16] I. S. Caleon and R. Subramaniam, "Do students know What they know and what they don't know? Using a four-tier diagnostic test to assess the nature of students' alternative conceptions," Res. Sci. Educ., vol. 40, no. 3, pp. 313-337, 2010.

[17] D. Kaltakci-Gurel, A. Eryilmaz, and L. C. McDermott, "Development and application of a fourtier test to assess pre-service physics teachers' misconceptions about geometrical optics," Res. Sci. Technol. Educ., vol. 35, no. 2, pp. 238-260, 2017.

[18] Effendy, A-Level Chemistry For Senior HIgh School Students, 2A ed. Malang: Bayumedia, 2012.

[19] J. E. McMurry and R. C. Fay, Chemistry, Sixth. New Jersey: Pearson Education, Inc., 2012.

[20] M. S. Silberberg, Chemisty-The Molecular Nature of Matter and Change, Fifth. New York: McGraw-Hill Companies, Inc, 2009.

[21] R. Chang, General Chemistry - The Essential Concepts, Fifth. New York: McGraw-Hill Companies, Inc, 2008.

[22] J. W. Creswell, Research - Planning, Conducting and Evaluating Quantitative and Qualitative Research, Fourth. Massachusetts: Pearson Education, Inc., 2012.

[23] G. Cakmakci, J. Leach, and J. Donnelly, "Students' ideas about reaction rate and its relationship with concentration or pressure," Int. J. Sci. Educ., vol. 28, no. 15, pp. 1795-1815, 2006.

[24] G. Cakmakci, "Identifying alternative conceptions of chemical kinetics among secondary school and undergraduate students in Turkey," J. Chem. Educ., vol. 87, no. 4, pp. 449-455, 2010.

[25] T. Turányi and Z. Tóth, "Hungarian university students' misunderstandings in thermodynamics and chemical kinetics," Chem. Educ. Res. Pract., vol. 14, no. 1, pp. 105-116, 2013.

[26] K. Bain, J.-M. G. Rodriguez, and M. H. Towns, "Investigating Student Understanding of Rate Constants: When is a Constant 'Constant'?, J. 
Chem. Educ., 2019.

[27] T. Gegios, K. Salta, and S. Koinis, "Investigating High-School Chemical Kinetics: The Greek Chemistry Textbook and Students' Difficulties," Chem. Educ. Res. Pract., vol. 18, no. 1, pp. 151-168, 2017.

[28] A. Kolomuç and S. Tekin, "Chemistry Teachers' Misconceptions Concerning Concept of Chemical Reaction Rate," Eurasian J. Phys. Chem. Educ., vol. 3, no. 2, pp. 84-101, 2011.

[29] A. Çam, M. S. Topçu, and Y. Sülün, "Preservice science teachers' attitudes towards chemistry and misconceptions about chemical kinetics," AsiaPacific Forum Sci. Learn. Teach., vol. 16, no. 2, pp. 12-14, 2015. 